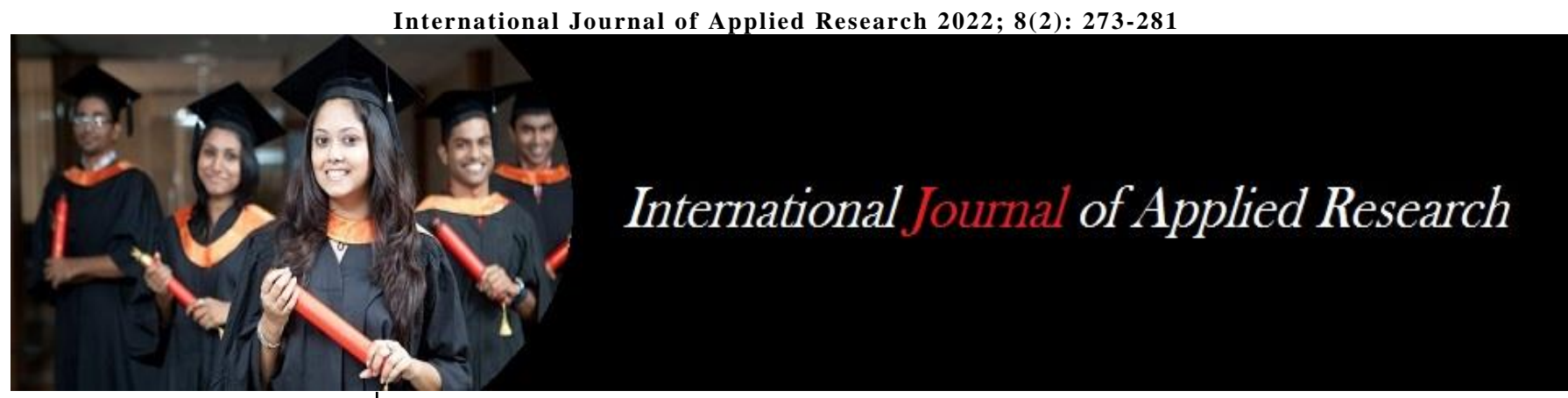

ISSN Print: 2394-7500

ISSN Online: 2394-5869

Impact Factor: 8.4

IJAR 2022; 8(2): 273-281

www.allresearchjournal.com

Received: 15-12-2021

Accepted: 25-01-2022

Dr. Aleena Mansoor

Post-Graduation $3^{\text {rd }}$ year,

Department of

Anaesthesiology, National

Institute of Medical Sciences \&

Research, Jaipur, Rajasthan,

India

Dr. Meenaxi Sharma

Professor and Principal,

Department of

Anaesthesiology, National

Institute of Medical Sciences

and Research, Jaipur,

Rajasthan, India

Dr. Anumeha Jain

Professor \& HOD, Department of Anaesthesiology, National Institute of Medical Sciences and Research, Jaipur,

Rajasthan, India
Corresponding Author:

Dr. Aleena Mansoor

Post-Graduation $3^{\text {rd }}$ year,

Department of

Anaesthesiology, National

Institute of Medical Sciences

and Research, Jaipur,

Rajasthan, India

\section{Comparative study between the characteristics of unilateral spinal and paravertebral neuraxial blockade in patients undergoing inguinal herniorrhaphy}

\author{
Dr. Aleena Mansoor, Dr. Meenaxi Sharma and Dr. Anumeha Jain
}

\section{Abstract}

Background: A Comparative study between the characteristics of unilateral spinal and paravertebral neuraxial blockade in patients undergoing inguinal herniorraphy.

Materials and Methods: This is a prospective, randomised study conducted on 120 patients of either sex, aged 18-60 years, ASA grade I and II scheduled for elective unilateral herniorraphy using unilateral spinal anaesthesia or paravertebral neuraxial blockade.

Results: The paravertebral anaesthesia group had shown significantly lesser requirement of postop analgesia, good quality of recovery and attainment of early ambulation as compared to unilateral spinal anaesthesia group. All the results were significant statistically and have correlated well with the studies in reference.

Conclusion: We concluded that the paravertebral block can be the choice of anaesthesia as a far superior and safe anaesthesia option to unilateral spinal anaesthesia for open unilateral inguinal hernia repair, as it yields unilateral and segmental anaesthesia, extended postoperative analgesia and decreased rescue analgesia demand postoperatively. Paravertebral block also helps in early ambulation, early readiness for discharge from hospital (bypass PACU), stable intra-operative hemodynamics, and minimal adverse effects.

Keywords: Ropivacaine, unilateral inguinal hernia, Spinal anaesthesia, paravertebral neuraxial block, Sensory block, motor block

\section{Introduction}

Inguinal hernia develops when fatty or intestinal tissue protrudes through a weakness in the abdominal wall near the left or right inguinal canal. Inguinal hernia repair is the most common performed surgery worldwide ${ }^{[1]}$. Hernia repair surgery needs anaesthesia and analgesia, so different anaesthetic techniques have been applied such as local anaesthetic infiltration, spinal/epidural anaesthesia with intravenous sedation and general anaesthesia ${ }^{[2]}$. In accord with the data collected, general anaesthesia has been given in $60-70 \%$ cases, central neuraxial blocks is given in 10-20\% cases and local infiltration anaesthesia is given in $5-15 \%$ cases ${ }^{[3]}$. The type of anaesthesia depends on several factors such as patient consent, duration and type of surgery - open/laproscopic, bilateral, recurrent/strangulated hernia and anaesthetic considerations ${ }^{[4]}$. Inguinal herniorrhaphy is not a short procedure, and if the patient is given general anaesthesia, there can be extended recuperation phase ${ }^{[5]}$. Local anaesthesia with the aid of using infiltration is frequently uncomfortable for hernia affected person ${ }^{[6]}$, a massive dose of anaesthetic drug can be required, and this approach is frequently augmented with heavy premedication or sedation, using drugs with decreased elimination ${ }^{5}$. Reasons for preferring regional anaesthesia is absence of unconsciousness, absence of respiratory depression, decrease in rates of post operative nausea and vomiting and rapid recuperation ${ }^{[7,8]}$. Local anaesthetic is deposited in the subarachnoid space which produces intense motor, sensory and sympathetic blockade in spinal anaesthesia or subarachnoid block. The increased popularity of this technique is due to the various advantages such as a concious patient, decreased metabolic stress response to surgery, decreased blood loss, decrease in pulmonary complications and reduced post- operative pain. 
However, there are certain disadvantages such as undesirable hemodynamic responses such as hypotension, bradycardia, prolonged motor blockade, urinary retention and post-spinal headache ${ }^{[9]}$. Paravertebral block (PVB) produces ipsilateral segmental analgesic effect through injection of local anaesthetics on all sides of the specific spinal nerve roots along the vertebral column ${ }^{[10]}$. This procedure has been used as anaesthesia for surgeries such as like breast surgeries, thoracotomies, inguinal hernia repair surgeries, renal surgeries and in chest trauma for analgesia ${ }^{[11]}$. This block generates segmental neural block, provides an appealing alternative in terms of greater hemodynamic control, extended post operative analgesia and decline in complications like post operative nausea vomiting (PONV), urinary retention and delay in ambulation ${ }^{[12]}$. Although these blocks are relatively simple and easy to learn and, when applied correctly, may have fewer side effects than general anaesthesia. However, they may result in potentially serious complications such as pneumothorax or epidural spread ${ }^{[13]}$. Ropivacaine, a long-acting amide local anaesthetic agent, is a pure $S(-)$ enantiomer of propivacaine. It has reduced potential for cardiotoxicity and neurotoxicity and is thus safer than the racemic preparation, bupivacaine. ${ }^{15}$ Ropivacaine can be used for epidural anaesthesia and analgesia, caudal block, spinal anaesthesia, peripheral nerve blocks, local infiltration, or intra-articular administration.

This study was conducted to evaluate and conclude the safety and efficacy of paravertebral block over unilateral spinal anaesthesia in patients undergoing inguinal hernia repair surgery.

\section{Materials and Methods}

Study design: An open labelled parallel group randomised controlled trial.

\section{Sample size: 120 patients.}

Sample size calculation: Sample size was calculated using software Epi Info TM ${ }^{[7]}$, with the assumption of alpha error to be $5 \%$ and beta error to be $20 \%$ i.e. $95 \%$ confidence interval and $80 \%$ power of study. Assumption of exposed group taken to be $95 \%$ with $10 \%$ margin of error. Thus a sample size of 120 patients was taken with 60 patients in each group.

Subjects \& selection method: All participants were randomly divided into two groups (Group S and Group P) by a computer generated randomization table.

Group S: Patients received Spinal Anaesthesia with $0.75 \%$ ropivacaine $5 \mathrm{ml}$

Group P: Patients received Paravertebral neuraxial block from $\mathrm{T} 10$ to $\mathrm{L} 1$ with $0.75 \%$ ropivacaine $5 \mathrm{ml}$ in each space.

\section{Inclusion Criteria}

- Age of the patient should be between 18-60 years.

- ASA status should be Grade I \& II.

- Patient should be undergoing elective unilateral inguinal hernia surgery.

- Patients should give informed consent for the surgery and anaesthesia.

\section{Exclusion Criteria \\ - Patient denial.}

- Any contraindication to spinal or lumber paravertebral block

- Patient is suffering from morbid obesity

- Patient has history of coagulopathy

- Any sign of infection at block site

- Any significant history of cardiovascular, respiratory, renal, hepatic and metabolic disease

- Any history of substance abuse, psychiatric disorders

- Any history of chronic analgesic use

- Any history of allergy to local anaesthetics

- Any episode of incomplete or failed block requiring GA

\section{Technique Methodology}

The patients in spinal anaesthesia group (Group S) were preloaded with $10 \mathrm{ml} / \mathrm{kg}$ of RL. Under all aseptic precautions, spinal anaesthesia was administered in lateral position (operative side dependant) with $25 \mathrm{G}$ Quincke spinal needle using midline approach at L2-L3 or L3-L4 intervertebral space. The subarachnoid injection was given with $5 \mathrm{ml}$ of. $75 \%$ ropivacaine. The patient was kept in the same lateral position for a time period of $10 \mathrm{mins}$ and then turned supine for surgery.

For the patients in Group P, a usual regional anaesthesia tray was put together; strict asepsis was maintained during block placement. An 8-cm, 22-gauge, Tuohy tip needle is being used for lumbar PVB. Similarly for thoracic paravertebral block, the needle with the depth markings on it or a guard indicating the depth is to be utilised. The needle is introduced by a fixed pre planned distance $(1.5-2.0 \mathrm{~cm})$ beyond the transverse process, without obtaining paraesthesia, is the method of choice used to perform lumbar paravertebral block. The block needle is inserted perpendicular to the skin unless the transverse process has come in contact. The depth at which the transverse process is contacted is varying (4-6 $\mathrm{cm}$ ) and depends on the build of the patient. When the transverse process has been identified, the marking on the needle is recorded or the depth marker is fixed so that it is $1.5-2.0 \mathrm{~cm}$ beyond the skin,that is the depth of transverse process. The needle is slowly taken out to the subcutaneous tissue and reinserted at a 10- to 15-degree caudad or caudal angle so that it glides off the superior or inferior edge of the transverse process. The needle is advanced forward by $1.5-$ $2.0 \mathrm{~cm}$ beyond the transverse process or until the depth marker has been touched. When there is negative aspiration for blood or cerebrospinal fluid (CSF), the local anaesthetic is injected into the space. Since the spread of local anaesthetic after giving a single large-volume lumbar paravertebral injection is not certain, the multiple-injection technique in which $4-5 \mathrm{~mL}$ of local anaesthetic is injected at each level is more often performed.

In both the groups, emergence of anaesthesia was evaluated by pin prick discrimination on the operative side at every 5 minutes interval upto 30 minutes interval. The block was regarded to be successful if the loss of pin prick discrimination was eminent within 15 minutes or if sensory block (T10-L1) was attained within 30 minutes.

\section{Data Recording}

The following parameters were assessed Intraoperatively, • Intraoperative baseline heart rate, heart rate was monitored at 2,5 interval for 15 minutes, then at 15 minutes interval till the surgery was completed and post operatively at 2, 4, 6, 12 and $24 \mathrm{hr}$ interval. Similarly systolic blood pressure, diastolic blood pressure and mean arterial pressure were also 
monitored using the same time parameters. Side effects like hypotension, bradycardia, PONV, pneumothorax etc were also monitored and noted. After completion of procedure, patients of both groups were shifted to the Postoperative Anaesthetic Care Unit (PACU) after complete evaluation of quality of recovery from anaesthesia and the patients were assessed for post operative pain, PONV, post operative analgesia requirement, $\mathrm{PDPH}$ and urinary retention at $6 \mathrm{hr}$, $12 \mathrm{hr}$, and $24 \mathrm{hr}$

\section{Statistical Analysis}

Data was presented as mean, standard deviation, median (range), or percentage, as appropriate. Study data was entered into the SPSS software (version 21, SPSS) and was analysed with the chi-square test for qualitative and student t-test for quantitative variables, between the trial and control groups, $\mathrm{P}$ values less than 0.05 was considered significant.

\section{Results}

Demographic Profile

(a) Age

Table 1: Demographic Profile - Age (Years) Distribution

\begin{tabular}{|c|c|c|c|c|}
\hline \multirow{2}{*}{ Age group (years) } & \multicolumn{2}{|c|}{ Group P } & \multicolumn{2}{c|}{ Group S } \\
\cline { 2 - 5 } & $\mathbf{N}$ & $\mathbf{\%}$ & $\mathbf{N}$ & $\mathbf{\%}$ \\
\hline 18-20 years & 1 & 1.67 & 2 & 3.33 \\
\hline 21-30 years & 6 & 10 & 5 & 8.33 \\
\hline 31-40 years & 13 & 21.67 & 11 & 18.33 \\
\hline 41-50 years & 18 & 30 & 18 & 30 \\
\hline 51-60 years & 22 & 36.67 & 24 & 40 \\
\hline Total & 60 & 100 & 60 & 100 \\
\hline
\end{tabular}

Chi square value $=0.67 \mathrm{P}=0.95 \mathrm{NS}$

Table 2: age Distribution

\begin{tabular}{|c|c|c|c|c|c|c|}
\hline & \multicolumn{3}{|c|}{ Group P } & \multicolumn{3}{c|}{ Group S } \\
\cline { 2 - 7 } & $\begin{array}{c}\text { Min- } \\
\text { Max }\end{array}$ & Mean & SD & $\begin{array}{c}\text { Min- } \\
\text { Max }\end{array}$ & Mean & SD \\
\hline $\begin{array}{c}\text { Age group } \\
\text { (years) }\end{array}$ & $18-60$ & 45.0 & 11.1 & $20-60$ & 45.88 & 11.3 \\
\hline
\end{tabular}

$\mathrm{P}$ value $=0.67 \mathrm{NS}$

The above tables represents the age distribution of the patients in Group P and Group S. The variable (age) was found to be normally distributed by Kolmogorov-Smirnov goodness-of-fit test. Applying statistical analysis (Student's unpaired $\mathrm{T}$ test), $\mathrm{p}$ value is found not to be significant $(\mathrm{p}=0.67)$.

\section{(b) ASA}

Table 3: ASA status

\begin{tabular}{|c|c|c|}
\hline ASA & Group P & Group S \\
\hline Grade 1 & $39(65 \%)$ & $34(56.67 \%)$ \\
\hline Grade 2 & $21(35 \%)$ & $26(43.33 \%)$ \\
\hline Total & $60(100 \%)$ & $60(100 \%)$ \\
\hline
\end{tabular}

The above table show the distribution of ASA status of the patients between Group P and Group S. This categorical variable (ASA Status) was tested by applying the Fisher's exact test 2-tailed test. It deduced that there was no statistical significance difference between the groups (c) Height and Body Weight

Table 4: Height, Weight and BMI:

\begin{tabular}{|c|c|c|c|}
\hline & Group P & Group S & P value \\
\hline Height & $166.72 \pm 6.6$ & $168.52 \pm 5.75$ & $0.11 \mathrm{NS}$ \\
\hline Weight & $73.1 \pm 6.68$ & $73.13 \pm 6.69$ & $0.98 \mathrm{NS}$ \\
\hline BMI & $26.33 \pm 2.16$ & $25.75 \pm 1.92$ & $0.12 \mathrm{NS}$ \\
\hline
\end{tabular}

The above table represents the height distribution of the patients between Group P and Group S. The variable (height) was found to be normally distributed by KolmogorovSmirnov goodness-of-fit test. After applying the statistical analysis (Student's unpaired T test), the $p$ value is found not to be significant $(\mathrm{p}=0.11)$.

The given table represents the weight distribution of the patients between Group P and Group S. The variable (weight) was found to be normally distributed by KolmogorovSmirnov goodness-of-fit test. After applying the statistical analysis (Student's unpaired T test), $\mathrm{p}$ value is found not to be significant $(\mathrm{p}=0.98)$.

\section{Pre-Operative Haemodynamics}

The following Table outlines the baseline HR, SBP, DBP and MAP between Group P and Group S. The variables (HR, SBP, DBP,MAP ) were normally distributed by KolmogorovSmirnov goodness-of-fit test. After applying the statistical analysis (Student's unpaired $T$ test), $\mathrm{p}$ value was found not to be significant.

\section{Intra Op \& Post Op Hemodynamic Parameters}

\section{(a) Heart Rate (bpm)}

Table 5: Comparison of Heart Rate At Different Time Periods

\begin{tabular}{|c|c|c|c|}
\hline Heart rate (bpm) & Group P & Group S & P value \\
\hline Baseline & $78.63 \pm 9.65$ & $78.3 \pm 10.33$ & 0.86 \\
\hline $2.5 \mathrm{~min}$ & $77.68 \pm 8.9$ & $77.52 \pm 9.84$ & 0.923 \\
\hline $5 \mathrm{~min}$ & $77.3 \pm 8.47$ & $76.93 \pm 9.31$ & 0.82 \\
\hline $7.5 \mathrm{~min}$ & $76.73 \pm 8.07$ & $76.2 \pm 8.46$ & 0.72 \\
\hline $10 \mathrm{~min}$ & $67.85 \pm 6.04$ & $69.33 \pm 7.69$ & 0.24 \\
\hline $10 \mathrm{~min}$ & $67.63 \pm 5.78$ & $67 \pm 7.71$ & 0.61 \\
\hline $12.5 \mathrm{~min}$ & $67.35 \pm 5.92$ & $64.88 \pm 6.49$ & 0.03 \\
\hline $15 \mathrm{~min}$ & $67.67 \pm 5.57$ & $64.7 \pm 6.49$ & 0.01 \\
\hline $30 \mathrm{~min}$ & $67.67 \pm 5.57$ & $64.7 \pm 6.49$ & 0.01 \\
\hline $45 \mathrm{~min}$ & $68.43 \pm 5.51$ & $65.37 \pm 7.05$ & 0.01 \\
\hline $1 \mathrm{hr}$ & $70.07 \pm 6.17$ & $67.75 \pm 6.26$ & 0.04 \\
\hline $2 \mathrm{hr}$ & $71.87 \pm 6.48$ & $68.48 \pm 6.35$ & 0.005 \\
\hline $4 \mathrm{hr}$ & $73.45 \pm 6.85$ & $69.93 \pm 6.57$ & 0.004 \\
\hline $6 \mathrm{hr}$ & $78.1 \pm 6.38$ & $76.27 \pm 5.96$ & 0.106 \\
\hline $12 \mathrm{hr}$ & $77.87 \pm 5.96$ & $77.55 \pm 5.24$ & 0.76 \\
\hline $24 \mathrm{hr}$ & $80 \pm 5.57$ & $79.95 \pm 5.52$ & 0.96 \\
\hline
\end{tabular}

The above Table the comparison between the heart rate baseline (HR_B) and at various time intervals after the blocks, e.g. $2.5 \mathrm{mins}$ (HR_2.5m), $5 \mathrm{mins}$ (HR_5m) etc upto 24 hours (HR_24h) between two groups. The variable (heart rate) was normally distributed by Kolmogorov-Smirnov goodness-of-fit test. After applying the Student's unpaired T test it was found that there was no statistically significant difference in HR between the groups ( $p$ value $<0.05$ ) except for the duration from $15 \mathrm{mins}$ to $4 \mathrm{hrs}$. In this time period, the patients of group $\mathrm{S}$ showed statistically significant decline in heart rate when compared to the patients of group $\mathrm{P}$. 


\section{(b) Systolic Blood Pressure (SBP)}

Table 6: Comparison of Systolic Blood Pressure at Different Time Periods

\begin{tabular}{|c|c|c|c|}
\hline SBP (mmHg) & Group P & Group S & P value \\
\hline Baseline & $136.07 \pm 8.25$ & $135.17 \pm 9.22$ & 0.57 \\
\hline $2.5 \mathrm{~min}$ & $126.48 \pm 7.9$ & $126.35 \pm 9.33$ & 0.93 \\
\hline $5 \mathrm{~min}$ & $122.8 \pm 8$ & $123.28 \pm 8.94$ & 0.76 \\
\hline $7.5 \mathrm{~min}$ & $118.93 \pm 8.97$ & $120.27 \pm 10.8$ & 0.46 \\
\hline $10 \mathrm{~min}$ & $116.82 \pm 8.95$ & $118.17 \pm 10.87$ & 0.46 \\
\hline $10 \mathrm{~min}$ & $115.67 \pm 8.95$ & $115.33 \pm 10.51$ & 0.85 \\
\hline $12.5 \mathrm{~min}$ & $116.02 \pm 7.82$ & $111.8 \pm 10.85$ & 0.02 \\
\hline $15 \mathrm{~min}$ & $117.9 \pm 7.47$ & $110.58 \pm 12.44$ & $<0.001$ \\
\hline $30 \mathrm{~min}$ & $117.9 \pm 7.47$ & $110.58 \pm 12.44$ & $<0.001$ \\
\hline $45 \mathrm{~min}$ & $119.78 \pm 6.88$ & $112.92 \pm 10.9$ & $<0.001$ \\
\hline $1 \mathrm{hr}$ & $120.37 \pm 14.6$ & $115.15 \pm 9.09$ & 0.02 \\
\hline $2 \mathrm{hr}$ & $123.32 \pm 6.28$ & $118.18 \pm 8$ & $<0.001$ \\
\hline $4 \mathrm{hr}$ & $125.25 \pm 6.88$ & $122.6 \pm 6.92$ & 0.04 \\
\hline $6 \mathrm{hr}$ & $125.68 \pm 6.76$ & $124.25 \pm 6.14$ & 0.23 \\
\hline $12 \mathrm{hr}$ & $127.43 \pm 6.38$ & $127.17 \pm 7.05$ & 0.83 \\
\hline $24 \mathrm{hr}$ & $129.7 \pm 5.9$ & $129.8 \pm 5.99$ & 0.93 \\
\hline
\end{tabular}

The above table shows the comparison of SBP baseline (SBP_B) and at various time intervals after the blocks, e.g. 2.5mins (SBP_2.5m), 5mins (SBP_5m) etc upto 24 hours (SBP_24h) between two groups. The variable (SBP) was normally distributed by Kolmogorov-Smirnov goodness-offit test. After applying the Student's unpaired T test it was found that there was no statistically significance difference in SBP between the groups ( $p$ value $<0.05$ ) except at $5 \mathrm{mins} \&$ for the duration from $15 \mathrm{mins}$ to $4 \mathrm{hrs}$. At $5 \mathrm{mins}$, patients of group P showed significant decrease in SBP whereas between 15 mins-4hrs the patients of group $S$ showed statistically significant decrease in SBP when compared to the patients of group $\mathrm{P}$.

\section{(c) Diastolic Blood Pressure (DBP)}

Table 7: Comparison of Diastolic Blood Pressure at Different Time Periods

\begin{tabular}{|c|c|c|c|}
\hline DBP (mmHg) & Group P & Group S & P value \\
\hline Baseline & $83.38 \pm 6.08$ & $82.03 \pm 5.77$ & 0.21 \\
\hline $2.5 \mathrm{~min}$ & $74.63 \pm 4.91$ & $75.92 \pm 4.89$ & 0.15 \\
\hline $5 \mathrm{~min}$ & $72.87 \pm 4.58$ & $73.8 \pm 5.46$ & 0.31 \\
\hline $7.5 \mathrm{~min}$ & $72.65 \pm 4.49$ & $70.98 \pm 6.04$ & 0.09 \\
\hline $10 \mathrm{~min}$ & $71.03 \pm 4.72$ & $69 \pm 5.8$ & 0.04 \\
\hline $10 \mathrm{~min}$ & $70.27 \pm 5.24$ & $68.05 \pm 5.75$ & 0.03 \\
\hline $12.5 \mathrm{~min}$ & $69.77 \pm 4.47$ & $66.88 \pm 7.14$ & 0.01 \\
\hline $15 \mathrm{~min}$ & $70.77 \pm 4.7$ & $67.05 \pm 8.34$ & $<0.001$ \\
\hline $30 \mathrm{~min}$ & $70.77 \pm 4.7$ & $67.05 \pm 8.34$ & $<0.001$ \\
\hline $45 \mathrm{~min}$ & $72.53 \pm 5.16$ & $69.07 \pm 7.8$ & $<0.001$ \\
\hline $1 \mathrm{hr}$ & $73.95 \pm 4.56$ & $70.57 \pm 6.04$ & $<0.001$ \\
\hline $2 \mathrm{hr}$ & $74.53 \pm 4.75$ & $72.02 \pm 5.02$ & 0.01 \\
\hline $4 \mathrm{hr}$ & $76.47 \pm 4.27$ & $74.72 \pm 5.02$ & 0.04 \\
\hline $6 \mathrm{hr}$ & $78.17 \pm 4.48$ & $76.63 \pm 4.77$ & 0.07 \\
\hline $12 \mathrm{hr}$ & $77.23 \pm 3.98$ & $78.18 \pm 4.22$ & 0.21 \\
\hline $24 \mathrm{hr}$ & $79.13 \pm 4.56$ & $80.13 \pm 3.49$ & 0.18 \\
\hline
\end{tabular}

The above table shows the comparison of DBP baseline (DBP _B) and at various time intervals after the blocks, e.g. $2.5 \mathrm{mins}$ (DBP_2.5m), 5mins (DBP_5min) upto 24 hours (DBP_24h) between two groups. The variable (DBP) was normally distributed by Kolmogorov-Smirnov goodness-of-fit test. After applying the Student's unpaired T test it was found that there was no statistically significant difference in DBP between the groups ( $\mathrm{p}$ value $<0.05$ ) except for the duration from 12.5 mins to $4 \mathrm{hrs}$. At this time period the patients of group $\mathrm{S}$ showed statistically significant decrease in DBP in comparison to the patients of group $\mathrm{P}$.

\section{(9) Mean Arterial Pressure}

Table 8: Comparison of Map (Mmhg) At Different Time Periods

\begin{tabular}{|c|c|c|c|}
\hline MAP & Group P & Group S & P value \\
\hline Base & $100.94 \pm 5.94$ & $99.74 \pm 5.96$ & 0.271 \\
\hline $2.5 \mathrm{~min}$ & $91.92 \pm 5.05$ & $92.73 \pm 6.01$ & 0.43 \\
\hline $5 \mathrm{~min}$ & $89.51 \pm 4.97$ & $90.29 \pm 5.99$ & 0.44 \\
\hline $7.5 \mathrm{~min}$ & $88.08 \pm 5.61$ & $87.41 \pm 7.1$ & 0.57 \\
\hline $10 \mathrm{~min}$ & $86.3 \pm 5.67$ & $85.39 \pm 6.95$ & 0.43 \\
\hline $10 \mathrm{~min}$ & $85.4 \pm 6.06$ & $83.81 \pm 6.65$ & 0.17 \\
\hline $12.5 \mathrm{~min}$ & $85.18 \pm 5.16$ & $81.86 \pm 8.02$ & 0.01 \\
\hline $15 \mathrm{~min}$ & $86.48 \pm 5.21$ & $81.56 \pm 9.38$ & 0 \\
\hline $30 \mathrm{~min}$ & $86.48 \pm 5.21$ & $81.56 \pm 9.38$ & 0 \\
\hline $45 \mathrm{~min}$ & $88.28 \pm 5.28$ & $83.68 \pm 8.4$ & 0 \\
\hline $1 \mathrm{hr}$ & $89.42 \pm 6.66$ & $85.43 \pm 6.53$ & 0 \\
\hline $2 \mathrm{hr}$ & $90.79 \pm 4.88$ & $87.41 \pm 5.13$ & 0 \\
\hline $4 \mathrm{hr}$ & $85.18 \pm 5.16$ & $81.86 \pm 8.02$ & 0.01 \\
\hline $6 \mathrm{hr}$ & $94.01 \pm 4.72$ & $92.51 \pm 4.63$ & 0.08 \\
\hline $12 \mathrm{hr}$ & $93.97 \pm 4.4$ & $94.51 \pm 4.7$ & 0.51 \\
\hline $24 \mathrm{hr}$ & $95.99 \pm 4.64$ & $96.69 \pm 3.67$ & 0.36 \\
\hline
\end{tabular}

The above table shows the comparison of MAP baseline (MAP_B) and at various time intervals after the blocks like 2.5mins (MAP_2.5m) upto 24 hours (MAP_24h) between two groups. The variable (MAP) was normally distributed by Kolmogorov-Smirnov goodness-of-fit test. After applying the Student's unpaired T test it was found that there was no statistically significance difference in MBP between the groups ( $p$ value $<0.05$ ) except for the duration from $15 \mathrm{mins}$ to $4 \mathrm{hrs}$.

\section{Modified Bromage score (MBS)}

Table 9: Comparison of Modified Bromage Scale At Different Time Periods

\begin{tabular}{|c|c|c|c|}
\hline MBS & Group P & Group S & P value \\
\hline $2 \mathrm{hr}$ & $5 \pm 0$ & $3.18 \pm 0.39$ & $<0.001 \mathrm{HS}$ \\
\hline $4 \mathrm{hr}$ & $6 \pm 0$ & $5 \pm 0$ & \\
\hline $6 \mathrm{hr}$ & $6 \pm 0$ & $6 \pm 0$ & \\
\hline $12 \mathrm{hr}$ & $6 \pm 0$ & $6 \pm 0$ & \\
\hline $24 \mathrm{hr}$ & $6 \pm 0$ & $6 \pm 0$ & \\
\hline
\end{tabular}

The above table shows the comparison of MBS between two groups. The variable (MBS) was skewed by KolmogorovSmirnov goodness-of-fit test. After applying the MannWhitney U-test it was found that there was no statistically significant difference in MBS between the groups ( $\mathrm{p}$ value < 0.05 ) except for the duration from $2 \mathrm{~h}$ to $4 \mathrm{~h}$. In this time period, the patients of group P showed statistically significant increase in MBS in comparison to the patients of group $S$

\section{VAS Score}

Table 10: Comparison of Vas Score At Different Time Periods:

\begin{tabular}{|c|c|c|c|}
\hline VAS & Group P & Group S & P value \\
\hline $2 \mathrm{hr}$ & $0 \pm 0$ & $1.47 \pm 0.5$ & $<0.001 \mathrm{HS}$ \\
\hline $4 \mathrm{hr}$ & $0 \pm 0$ & $0.65 \pm 0.48$ & $<0.001 \mathrm{HS}$ \\
\hline $6 \mathrm{hr}$ & $1.67 \pm 0.48$ & $1.65 \pm 0.48$ & $0.85 \mathrm{NS}$ \\
\hline $12 \mathrm{hr}$ & $1.05 \pm 0.22$ & $3.27 \pm 0.45$ & $<0.001 \mathrm{HS}$ \\
\hline $24 \mathrm{hr}$ & $2.55 \pm 0.5$ & $2.38 \pm 0.49$ & $0.07 \mathrm{NS}$ \\
\hline
\end{tabular}


The above table shows the comparison of VAS score between two groups. The variable (VAS score) was skewed by Kolmogorov-Smirnov goodness-of-fit test. After applying the Mann-Whitney U-test it was concluded that there was statistically significant difference in VAS score between the two groups for the duration from $2 \mathrm{~h}$ to $4 \mathrm{~h} \& 12 \mathrm{~h}$. In this time period, the patients of group $\mathrm{S}$ presented with statistically significant increase in VAS score when compared with the patients of group $\mathrm{P}$.

\section{Modified Aldrete Score (MAS)}

Table 11: Comparison of Mas at Different Time Periods

\begin{tabular}{|c|c|c|c|}
\hline MAS & Group P & Group S & P value \\
\hline $2 \mathrm{hr}$ & $10 \pm 0$ & $10 \pm 0$ & \\
\hline $4 \mathrm{hr}$ & $10 \pm 0$ & $10 \pm 0$ & \\
\hline $6 \mathrm{hr}$ & $10 \pm 0$ & $10 \pm 0$ & \\
\hline $12 \mathrm{hr}$ & $10 \pm 0$ & $10 \pm 0$ & \\
\hline $24 \mathrm{hr}$ & $10 \pm 0$ & $10 \pm 0$ & \\
\hline
\end{tabular}

The above table shows the comparison of MAS between two groups. The variable (MAS) was skewed by KolmogorovSmirnov goodness-of-fit test. After applying the MannWhitney U-test it was concluded that there was statistically no difference present in MAS score between the two groups.

\section{Post operative nausea vomiting}

The following table shows the distribution of PONV (' 0 ' no PONV, ' 1 ' PONV occurred) of the patients between Group P and Group S. This categorical variable (PONV) was tested by applying the Fisher's exact test 2-tailed test and it was found that there was statistically significant difference between the groups.

\section{Shivering}

The following table shows the distribution of shivering (' 0 ' no shivering, ' 1 ' shivering occurred) between Group P and Group S. The categorical variable was tested by applying the Fisher's exact test 2-tailed test and it was found that there was statistically significant difference between the groups.

\section{Comparison of urinary retention}

The following table shows the distribution of urinary retention (' 0 ' no retention, ' 1 ' retention requiring treatment) between Group P and Group S. The categorical variable was tested by applying the Fisher's exact test 2-tailed test and it was found that there was significant difference between the groups.

\section{Comparison of bloody puncture}

The following table shows the distribution of bloody puncture ('0' no bloody puncture, ' 1 ' bloody puncture) between Group $\mathrm{P}$ and Group $\mathrm{S}$. The categorical variable was tested by applying the Fisher's exact test 2-tailed test and it was found that there was no statistically significant difference between the groups.

Table 12: Comparison of Side Effects

\begin{tabular}{|c|c|c|c|}
\hline Side effects & Group P & Group S & P value \\
\hline PONV & $0(0 \%)$ & $8(13.33 \%)$ & $0.006 \mathrm{HS}$ \\
\hline Shivering & $0(0 \%)$ & $9(15 \%)$ & $0.004 \mathrm{HS}$ \\
\hline Arrhythmia & $0(0 \%)$ & $0(0 \%)$ & \\
\hline Headache & $0(0 \%)$ & $0(0 \%)$ & \\
\hline LAST & $0(0 \%)$ & $0(0 \%)$ & \\
\hline Urine retention & $0(0 \%)$ & $7(11.67 \%)$ & $0.01 \mathrm{~S}$ \\
\hline Bloody Puncture & $2(3.33 \%)$ & $2(3.33 \%)$ & $1.00 \mathrm{NS}$ \\
\hline Pneumothorax & $0(0 \%)$ & $0(0 \%)$ & \\
\hline Vasovagal & $3(5 \%)$ & $0(0 \%)$ & $0.087 \mathrm{NS}$ \\
\hline
\end{tabular}

There was no incidence of partial blockade or failed blockade requiring converting the block to general anaesthesia and no incidence of any serious side effects like local anaesthetic systemic toxicity (LAST), inadvertent intravascular injection and pneumothorax were detected in our study while giving paravertebral block.

\section{Discussion}

The surgery for inguinal hernia repair is becoming one of the most common general surgical operative procedures. Even though the laparoscopic repair is becoming increasingly popular, open repair is still considered the most common option. It is often performed as a day care procedure with the main aim to achieve good post operative analgesia, reduced hospital stay and opting for an anaesthesia technique with least side effects.

Spinal anaesthesia is the most common anaesthesia technique used for repair of inguinal hernia, inspite of having various adverse side effects like post dural puncture headache, incidences of urinary retention, motor blockage of lower extremities, significant intraoperative hemodynamic variations, delay in achieving mobility and delay in discharge from the hospital ${ }^{[3,41-43]}$. The demand for the fast-track ambulatory surgery has opened up various other alternative methods of regional anaesthesia like paravertebral block, peripheral nerve block, Bier's block in an attempt to avoid the common side effects of central neuraxial block ${ }^{[44]}$.

The usage of unilateral spinal anaesthesia has frequently been suggested for almost all outpatient procedures, particularly lower extremity surgeries. This procedure requires positioning the patient in a lateral position for $5-15 \mathrm{mins}$ to allow concentration of the anaesthetic to reach and effect in the dependant leg. Due to this technique, lower dose of drug can be administered, but this procedure does not appear to facilitate faster recovery despite reduced pain and decreased prevalence of nausea in PACU. It can be restricted to the patients at higher risk for nausea, and to where this block can be performed in an induction area ${ }^{45}$.

The paravertebral block is a technique of regional anaesthesia that involves the injection of local anaesthetics at required multiple levels immediately lateral to the vertebral column into the paravertebral space from where the spinal nerves are emerging from the intervertebral foramina and bifurcating into the dorsal and ventral rami ${ }^{[28]}$. The various limitations of 
paravertebral block are that this technique is time consuming, there is prevalence patient discomfort and pain from multiple injections on multiple levels, high chances of pneumothorax and increased risk of inadvertent intravascular injection ${ }^{[24]}$. All these factors make it a less popular choice as compared to spinal or epidural anaesthesia.

In this current study, the safety and efficacy of paravertebral block has been compared with unilateral spinal anaesthesia in inguinal hernia repair in non ambulatory setting.

One hundred and twenty consenting male patients, aged between 18-60 years, ASA physical status I \& II, undergoing elective open inguinal herniorrhaphy were taken up for this prospective interventional study and were divided into two groups, Group P $(n=60)$ \& S $(n=60)$ for receiving either paravertebral block or unilateral spinal anaesthesia.

The sample size for this current study was calculated on the basis of time to administer the first rescue analgesic as a predominant outcome.

The patients were monitored for first 24 hours postoperatively and the duration of post operative analgesia was noted by recording the time to first post- operative rescue analgesic administration from the time of placement of the block. In addition, the following parameters were also monitored like total analgesic consumption in first 24 hours post-operatively, the time taken for block performance, the block characteristics like time of onset of sensory block, time to reach peak level of sensory block, time taken to recovery from sensory \& motor blockade (modified Bromage score), time to reach ambulation, time to reach discharge criteria (modified Aldrete score), the Visual analog scale and prevalence of side effects (PONV, shivering, urinary retention, bloody puncture, local anaesthetic systemic toxicity and pneumothorax) were also noted

The suggestion of paravertebral block for inguinal hernia repair surgeries was proposed by Wassef et al. ${ }^{[25]}$ in 1998. They compared paravertebral blocks with field blocks. The paravertebral technique showed a significantly increased success rate when compared with the field blocks, in regard to the frequency of pain relative to surgical handling of spermatic cord, and hernia sac. It requires less local anaesthetic usage and less needle insertion than when compared with the field block and they concluded that paravertebral nerve root block is far superior to the field blocks, it is devoid of any adverse side effects, and acceptable to the patients.

Later Klein et al. ${ }^{[27]}$ in 2002 compared paravertebral block with the peripheral neural blocks for the requirement of postoperative analgesia in patients undergoing inguinal hernia repair surgery under general anaesthesia and deduced that paravertebral block induces analgesia equivalent to extensive peripheral nerve block, thus offering an attractive alternative method of postoperative pain management with significantly fewer side effects.

Weltz et al. ${ }^{[28]}$ in 2003 evaluated the effectiveness of paravertebral block in inguinal hernia repair surgeries as an ambulatory procedure and thus found that paravertebral block gave minimum postoperative pain and far less use of narcotics, lower prevalence of nausea and vomiting, and shorter duration of hospital stay.

Later these results were confirmed by Hadzic et al. ${ }^{[29]}$ in 2006, who then compared paravertebral anaesthesia with general anaesthesia for inguinal hernia repair surgeries.

Again Naja et al. ${ }^{[46]}$ in 2006, compared the effectiveness of nerve stimulator guided paravertebral block with that of ilio- inguinal nerve block in children undergoing inguinal herniorrhaphy and further observed that better patient satisfaction is achieved in paravertebral block group.

In a study, Isil et al. ${ }^{[34]}$ in 2014, also found extended analgesia paravertebral block group than in conventional spinal anaesthesia.

In this current study demographic parameters (age, height, weight), ASA physical status and baseline haemodynamics were comparable in both the groups.

Age

The value of mean age of patients in Group $\mathrm{P}$ is 45.0 and Group $S$ is 45.88 . There is no statistical significant difference in age in both groups

\section{Height And Body Weight}

The value of mean body weight of patients in Group P and Group $\mathrm{S}$ has no significant statistical difference when comparison was done $(\mathrm{p}=0.98)$

Similarly, the value of mean height of patients in Group P and Group $S$ has no significant statistical difference when the comparison was done $(\mathrm{p}=0.11)$

\section{Hemodynamins}

The monitored intra-operative and post-operative haemodynamic parameters were significantly different in both the groups.

The patients who were in group $S$ showed statistically significant $(\mathrm{p}<0.05)$ decrease in heart rate when compared to the patients from group $\mathrm{P}$ from $15 \mathrm{mins}$ to 4 hours of postblock period.

The patients who were in group $S$ showed statistically significant $(p<0.005)$ decrease in SBP when compared with the patients from group $\mathrm{P}$ between $15 \mathrm{mins}-4 \mathrm{hrs}$ of post-block period.

The patients who were in group $S$ showed statistically significant $(\mathrm{p}=0.000)$ decrease in DBP when compared with the patients from group $\mathrm{P}$ between $15 \mathrm{mins}-4 \mathrm{hrs}$.

The patients who were in group $S$ showed statistically significant $(\mathrm{p}<0.05)$ decrease in MAP when compared with the patients from group P from $12.5 \mathrm{mins}$ to $4 \mathrm{hrs}$.

In paravertebral group, there is reduced haemodynamic derangement due to only unilateral segmental sympathetic block (T10-L1). Due to more anterior placement of sympathetic chain in the paravertebral space there is prevalence of decreased sympathetic block in paravertebral technique. However, in unilateral spinal anaesthesia group, autonomic block extends 2-4 segment above the level of injection, which further leads to greater fall in heart rate, systolic blood pressure, diastolic blood pressure, mean arterial pressure and also the peak level of sensory block was significantly increased in Group S (upto T4) than when compared to Group P (upto T8) $(\mathrm{P}<0.001)$.

There were findings similar to the study by Akcaboy et al. [31], who also found that the patients suffer reduced haemodynamic derangement after paravertebral block than in unilateral spinal anaesthesia.

But in the studies by Mandal et al. ${ }^{[33]}$ and Madishetti et al. ${ }^{[40]}$, intraoperative vitals were comparable in both the groups which may be due to use of reduced volume of drug $8 \mathrm{mg}$ of hyperbaric bupivacaine for spinal anaesthesia and keeping the patient in lateral position for a longer duration of $15 \mathrm{mins}$ which limited the height of the block. 
In the current study $15 \mathrm{mg}$ of. $75 \%$ ropivacaine was administered and patient was kept lateral position for 10mins. In the studies by Mandal et al. ${ }^{[33]}$ in and Madishetti et al. ${ }^{[40]}$ block height was not documented.

\section{Block Characteristics}

The duration of analgesic used which was estimated by time to administration of first dose of rescue analgesic was significantly longer $(\mathrm{p}=0.000)$ in group $\mathrm{P}(8.55 \pm 0.72$ hours $)$ in comparison with the group $\mathrm{S}$ ( $3.01 \pm 0.44$ hours) in this study. This finding is similar to a study by Aswin et al. ${ }^{[11]}$ who documented the time of first rescue post operative analgesia as $348 \pm 39$ mins in group $P$ and $207 \pm 26$ mins in group S.

Nikam et al. ${ }^{[36]}$ found that post op analgesia lasted for $324 \pm 52.84 \mathrm{mins}$ in group $\mathrm{P}$ and $182 \pm 40.13$ mins in group $\mathrm{S}$.

Madishetti et al. ${ }^{[40]}$ documented this to be $341 \pm 66 \mathrm{mins}$ in group $\mathrm{P}$ and $209 \pm 18 \mathrm{mins}$ in group $\mathrm{S}$. This is most likely due to avascularity of paravertebral space which leads to slow uptake and distribution of local anaesthetic and usage of larger amount of drug in paravertebral block than in unilateral spinal anaesthesia.

But two authors Khetarpal et al. ${ }^{[39]}$ and Mishra et al. ${ }^{[38]}$ documented a much higher duration of sensory analgesia in paravertebral group, $15.17 \pm 3.35$ hours and $14.133 \pm 2.255$ hours respectively. Khetarpal et al. ${ }^{[39]}$ used $30 \mathrm{ml}$ of LA in paravertebral space compared to $20 \mathrm{ml}$ in the present study and others ${ }^{[11,77,81]}$ which may have led to longer duration of analgesia.

The total requirement of rescue analgesic in $24 \mathrm{hrs}$ was significantly higher in Group S in comparison to Group P ( $p<$ 0.001).

The time taken to reach recovery from sensory block was significantly increased in group $\mathrm{P}$ when compared with group $\mathrm{S}(\mathrm{p}=0.000)$, but time to recovery from motor $\operatorname{block}(\mathrm{p}=0.000)$ and time to ambulation $(\mathrm{p}=0.000)$ were significantly reduced in group $\mathrm{P}$ than in group $\mathrm{S}$ as there was no motor block in group P. All of these findings were in favour of paravertebral block in inguinal hernia surgery as a day care procedure and were similar to the results found in a study by Mishra et al. [38].

The patients who were in group $S$ showed statistically significant $(\mathrm{p}=0.000)$ increase in VAS score when compared with the patients from group $\mathrm{P}$ from $2 \mathrm{~h}$ to $4 \mathrm{~h} \& 12 \mathrm{~h}$ of postblock period. Group $\mathrm{P}$ showed statistically significant $(\mathrm{p}=0.000)$ increase in modified Bromage Score in comparison to group $\mathrm{S}$ for the duration from $2 \mathrm{~h}$ to $4 \mathrm{~h}$. The Group $\mathrm{P}$ showed statistically significant $(\mathrm{p}=0.000)$ increase in modified Aldrete score in comparison to group $\mathrm{S}$ at upto 4hours beyond block performance after which the score was similar in both the groups.

Thus paravertebral block can be more beneficiary for providing shorter hospital stay and early discharge and these findings are similar to the studies done by Sinha et al. ${ }^{[10]}$, Khetarpal et al. ${ }^{[39]}$ and Madishetti et al. ${ }^{[40]}$.

The duration of time taken to perform the block and time to reach loss of pin-prick sensation were significantly $(\mathrm{p}=0.000)$ less in group $\mathrm{S}$ in comparison to the patients of group $\mathrm{P}$ and it was found that patients in group $S$ the block level reaches T10 dermatome significantly $(\mathrm{p}=0.001)$ earlier when compared to group $\mathrm{P}$. The time taken for block performance time was higher in paravertebral group as it was a significantly less familiar technique and needed greater skill. Multiple injections were needed to be administered at 4 different vertebral levels. If the block was given using nerve stimulator technique in place of anatomical landmarks, additional time was required to adjust the current in the nerve stimulator after eliciting muscle contraction. The time to reach block onset was also significantly increased in paravertebral group as the drug had to travel a longer distance to reach the neural tissue as compared in spinal anaesthesia the drug was injected directly into the subarachnoid space. These findings were similar to the findings of Varma et al. [37]. They deduced that subarachnoid block is more superior than paravertebral block in unilateral inguinal hernia repair surgeries in terms of time required for performing the procedure, effectiveness, comfort of the patient \& surgeons satisfaction.

There was negative prevalence of partial block or failed block which required conversion to general anaesthesia. Mandal et al. ${ }^{[33]}$, Hadzic et al. ${ }^{[29]}$, Aswin et al. ${ }^{[11]}$ had 100 percent success rate even after employing blind technique.

The prevalence of pneumothorax in paravertebral block is $0.5 \%$ was documented by Lonnqvist et al. ${ }^{[24]}$ The prevalence of developing pneumothorax increases if paravertebral block is performed in upper thoracic level. Similarly, in all the previous studies regarding paravertebral block in inguinal hernia repair surgery, there was no prevalence of pneumothorax in the present study as the block was performed in lower thoracic and lumber vertebral level (lower level of pleura is T12).

There was negative incidence of local anaesthetic systemic toxicity or intravascular injection in any of the groups even after multiple injections were administered in the paravertebral group. The prevalence of bloody puncture was slightly higher (p-1.000) in paravertebral group.

The incidences of postoperative nausea vomiting, incidence of shivering and urinary retention were slightly higher in unilateral spinal group which was in accordance to a study by Madishetti et al. ${ }^{[40]}$ In all previous studies incidences of PONV \& urinary retention were significantly higher in spinal group. This differnce of result is mainly due to use of unilateral spinal anaesthesia rather than conventional spinal anaesthesia in the current study. The occurence of PONV is higher in conventional spinal anaesthesia due to widespread sympathetic blockade causing significant hemodynamic changes. There is negative event of urinary retention after paravertebral block due to parasympathetic fibres that innervate urinary bladder are not being blocked during this technique.

Thus paravertebral block was observed to cause only segmental sensory blockade and no motor blockade to patients compared to spinal anaesthesia. This along with the fact that paravertebral block is associated with prolonged analgesia makes it a valuable and safe mode of anaesthesia for inguinal hernia repair to make the patient ambulatory soon.

The small sample size was one of the limitations of this current study, so further studies should be done with a much larger population size. This current study was an open label study as blinding was not possible because of the difference between the two procedures used. Another limitation of the study was that we were in the starting phase of practicing the paravertebral block technique. Due to the lack of experience, practice and skill there was increase in the performance of the block time in paravertebral group, whereas keeping the patient in lateral position for 10 - 15 minutes after inducing spinal anaesthesia delayed the start of surgery. 


\section{Conclusion}

In my current study, the paravertebral block can be the choice of anaesthesia as a far superior and safe anaesthesia option to unilateral spinal anaesthesia for open unilateral inguinal hernia repair, as it yields unilateral and segmental anaesthesia, extended postoperative analgesia and decreased rescue analgesia demand.

Paravertebral block also helps in early ambulation, early readiness for discharge from hospital (bypass PACU), stable intra-operative hemodynamics, and minimal adverse effects. However, main concerns are the skill required to execute, procedure-related time and extended onset of effect.

\section{References}

1. Baskerville PA, Jarret PEM. Day case inguinal hernia. Ann R Coll Surg Engl.1983;65:224-5.

2. Young DV. Comparison of local, spinal and general anaesthesia for inguinal hernia repair. Am J Surg. 1987;153:560-3

3. Kehlet H, White PF. Optimising anaesthesia for inguinal herniorrhaphy: General, regional or local anesthesia? Anesth Analg. 2001;93:1367-9.

4. Conroy JM, Othersen HB, Dorman BH. A comparison of wound instillation and caudal block for analgesia following paediatric inguinal herniorraphy. J Pediatr Surg. 1993;28:565-567.

5. Wood GJ, Lloyd JW, Bullingham RES, Britton BJ, Finch DRA. Postoperative analgesia for day-case herniorrhaphy patients. Anaesthesia. 1981;36:603-610.

6. Oosterlee J, Dudley H. Surgery in outpatients. British Medical Journal. 1979;2:1459-60.

7. Cwik J. Postoperative considerations of neuraxial anesthesia. Anesthesiol Clin. 2012;30:433-43.

8. Aklaya F. Postoperative complications and nausea vomiting. Turkiye Klinikleri J Anest Reanim-Special Topics. 2008;1:112-6.

9. O'Dower PJ, Serpell MG, Millar K, Paterson C, Young D, Hair A et al. Local or general anaesthesia for open hernia repair: a randomized trial. Ann Surg. 2003;237:574-9

10. Sinha SK, Brahmchari Y, Kaur M, Jain A. The comparative evaluation of safety and efficacy of unilateral paravertebral block with conventional spinal anesthesia for inguinal hernia repair. Indian J Anaesth. 2016;60:499-505

11. Aswin AB, Suresh YV. Comparison of paravertebral block with spinal anaesthesia in unilateral inguinal hernia repair. International J Scientific Research Publications. 2015;5:2250-3153.

12. Bhattacharya P, Mandal MC, Mukhopadhyay S, Das S, Pal PP, Basu SR. Unilateral paravertebral block: An alternative to conventional spinal anaesthesia for inguinal hernia repair. Acta Anaesthesiol Scand. 2010;54:246-51

13. Thavaneswaran P, Cooter RD, Perera CL, Maddern G. J. Paravertebral block for anaesthesia. Anaesthesia Analgesia. 2010;110:1740-44.

14. Richard W, Rosenquist MD, Bruce M, Vrooman MD. Chronic Pain management.In: Brian Belval and Harriet Lebowitz, editor. Morgan GE, Mikhail's Clinical Anesthesiology. $5^{\text {th }}$ ed.: Mc Graw Hill Education. 2013;47:1034-37
15. Simpson D, Curran MP, Oldfield V, Keating GM. Ropivacaine: A review of its use in regional anaesthesia and acute pain management. Drugs. 2005;65:2675-717.

16. Gorelick PB, Zych D. James Leonard Corning and the early history of spinal puncture (abstract). Neurology.1987;37(4):672-4.

17. Bier A. Experiments on cocainization of spinal cord. Deutsche Zeitschrift fur Chirurgie (in German). 1899;51:361-9.

18. Jonnesco $\mathrm{T}$. General spinal analgesia. $\mathrm{Br}$ Med $\mathrm{J}$. 1909;2(2550):1396-1401

19. Lund PC, Rumball AC. Hypobaric pontocaine spinal anaesthesia. 1640 consecutive cases. Anaesthesiology. 1947;8:181-99

20. Tanasichuk MA, Shultz EA, Matthews JH, Van Bergen F. spinal hemianalgesia: an evaluation of a method, its applicability and influence on the incidence of hypotension. Anesthesiology. 1961;22:74-85.

21. Karmakar MK. Thoracic paravertebral block. Anaesthesiology. 2001;95:771-80.

22. Shaw WM. Medial approach for paravertebral somatic nerve block. Journal of the American Medical Association. 1952;148:742-4.

23. Eason MJ, Wyatt R. Paravertebral thoracic block-a reappraisal. Anesthesia. 1979;34:638-642.

24. Lonnqvist PA. Paravertebral blockade: Failure rate and complications. Anaesthesia. 1995;50:813-15.

25. Wassef MR, Randazzo T, Ward W. The paravertebral nerve root block for inguinal herniorraphy-a comparison with the field block approach. Reg Anesth Pain Med. 1998;23(5):451-6

26. Naja Z, Lonnqvist PA. Somatic paravertebral nerve blockade. Incidence of failed block and complications. Anaesthesia. 2001;56:1184-88.

27. Klein S, Pietrobon R, Nielsen K. Paravertebral somatic nerve block compared with peripheral nerve block for outpatient inguinal herniorrhaphy. Reg Anesth Pain Med. 2002;27:476-80

28. Weltz CR, Klein SM, Arbo JE, Greengrass RA. Paravertebral block anaesthesia for inguinal hernia repair. World J Surg. 2003;27:425-29.

29. Hadzic A, Kerimoglu B, Loreio D, Karaca PE, Claudio RE, Yufa M et al. Paravertebral blocks provide superior same-day recovery over General anaesthesia for patients undergoing inguinal hernia repair. Anesth Analg. 2006;102:1076-81.

30. Naja MZ, Ziade MF, El Rajab M. Varying anatomical injection points within the thoracic paravertebral space: effect on spread of solution and nerve blockade. Anesthesia. 2004;59(5):459-63.

31. Akcaboy EY, Akcaboy ZN, Gogus N. Ambulatory inguinal herniorrhaphy: paravertebral block versus spinal anaesthesia. Minerva anestesiol. 2009;75:684-91.

32. Chaudhary S, Azad R, Kumar A, Bhattacharya N. Efficacy and Effect on Autonomic Functions by Paravertebral Block, with/without Opioid Neuroaugmentation for Inguinal Herniorrhaphy. J Anaesth Clin Pharmacol. 2009;25(3):316-320.

33. Mandal M, Das S, Gupta S, Ghosh TR, Basu SR. Paravertebral block can be an alternative to unilateral spinal anaesthesia for inguinal hernia repair. Indian $\mathbf{J}$ Anaesth. 2011;55:584-89

34. Isil CT, Cinar ASO, Oba S, Isil RG. Comparison of spinal anaesthesia and paravertebral block in unilateral 
inguinal hernia repair. Turk $\mathbf{J}$ Anaesthesiol Reanim. 2014;42:257-263

35. Lawrence Siu-Chun Law, Mingjuan Tan, Yaowu Bai, Timothy E Miller, Yi-Ju Li, Tong-Joo Gan. Paravertebral Block for Inguinal Herniorrhaphy: A Systematic Review and Meta-Analysis of Randomized Controlled Trials. Anesthesia analgesia. 2015;121(2):556-569

36. Nikam SG, Lawhle SS, Lalwani DL, Bhagat J. Clinical trial for the effectiveness of unilateral paravertebral block versus unilateral subarachnoid block in unilateral inguinal hernia for herniorrhaphy. J Res Med Dent Sci. 2015;3:176-81

37. Varma P, Ninave S. Comparison of Paravertebral Block with Spinal Anaesthesia in Unilateral Inguinal Hernia Repair. International Journal of Science and Research. 2016;5(12):475-78.

38. Mishra M, Mishra SP, Singh SP. Comparison of spinal with paravertebral block for elective open inguinal hernia repair. World J Med Res. 2016;5:1-6.

39. Khetarpal R, Chatrath V, Kaur A, Jassi R, Verma R. Comparison of Spinal Anesthesia and Paravertebral Block in Inguinal Hernia Repair. Anesthesia. 2017;11(3):724-29

40. Madishetti ER, Jain R, Pullela RP. Paravertebral block versus unilateral spinal anesthesia for inguinal hernia repair-A comparative clinical trial. Asian pacific journal of health sciences. 2017;4(4):177-181.

41. Khetarpal R, Chatrath V, Kaur A, Jassi R, Verma R. Comparison of Spinal Anesthesia and Paravertebral Block in Inguinal Hernia Repair. Anesthesia. 2017;11(3):724-29

42. Madishetti ER, Jain R, Pullela RP. Paravertebral block versus unilateral spinal anesthesia for inguinal hernia repair-A comparative clinical trial. Asian pacific journal of health sciences. 2017;4(4):177-181.

43. Ozgun H, Kurt MN, Kurt I, Cevikel MH. Comparison of local, spinal and general anesthesia for inguinal herniorrhaphy. Eur J Surg. 2002;168:455-9.

44. Yilmazlar A, Bilgel H, Donmez C, Guney A, Yilmazlat $\mathrm{T}$, Tokat O. Comparison of ilioinguinal-iliohypogastric nerve block versus spinal anesthesia for inguinal herniorrhaphy. South Med J. 2006;99:48-51.

45. Mulroy MF. Ambulatory surgery. A practical approach to regional anaesthesia ${ }^{\text {th }}$ ed. Mulroy MF, Bernards CM, McDonald SB, Salians FV. Lippincott Williams \& Wilkins, a Wolters Kluwer. 2009, 311.

46. Naja ZM, Raf M, Rajab M, Daoud N, Ziade FM, Tannir MA, Lonnqvist PA. A comparison of nerve stimulator guided paravertebral block and ilio-inguinal nerve block for analgesia after inguinal herniorrhaphy in children. Anaesth. 2006;61(11):1064-1068. 